\title{
Mario Lavagetto, Variazioni su una metafora
}

\section{Marco Stupazzoni}

\section{(2) OpenEdition}

\section{Journals}

\section{Edizione digitale}

URL: http://journals.openedition.org/studifrancesi/6011

DOI: 10.4000/studifrancesi.6011

ISSN: 2427-5856

\section{Editore}

Rosenberg \& Sellier

\section{Edizione cartacea}

Data di pubblicazione: 1 mai 2011

Paginazione: 187

ISSN: 0039-2944

\section{Notizia bibliografica digitale}

Marco Stupazzoni, «Mario Lavagetto, Variazioni su una metafora», Studi Francesi [Online], 163 (LV | I) |

2011, online dal 30 novembre 2015, consultato il 08 janvier 2021. URL: http://

journals.openedition.org/studifrancesi/6011 ; DOI: https://doi.org/10.4000/studifrancesi.6011

Questo documento è stato generato automaticamente il 8 janvier 2021.

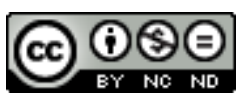

Studi Francesi è distribuita con Licenza Creative Commons Attribuzione - Non commerciale - Non opere derivate 4.0 Internazionale. 


\title{
Mario Lavagetto, Variazioni su una metafora
}

\author{
Marco Stupazzoni
}

\section{NOTIZIA}

MARIo LAVAGETto, Variazioni su una metafora, con tavole di Sergio Romiti, Parma, MUP, Università degli Studi di Parma, Facoltà di Architettura, 2008, pp. 91.

1 Lo studio di Mario Lavagetto che qui presentiamo costituisce la nuova versione, rivista, corretta ed ampliata, della prolusione tenuta dal critico presso la Facoltà di Architettura dell'Università degli Studi di Parma nell'anno accademico 2006-2007 («Metafore di confine tra architettura e letteratura»).

2 La metafora assunta come oggetto specifico di studio da Lavagetto è quella che rimanda in modo diretto all'architettura, il cui uso è descritto ed analizzato attraverso opere letterarie, quali La Comédie humaine di Balzac, Notre-Dame de Paris di Victor Hugo e À la Recherche du temps perdu di Marcel Proust.

3 Intimamente legati al concetto di struttura («la struttura - scrive l'A. - è il principio di organizzazione di un sistema che si può scoprire e descrivere e che si manifesta nella percezione estetica di un'opera», p. 27), il linguaggio dell'architettura e il linguaggio poetico risultano, nelle opere degli scrittori considerati, strettamente complementari.

4 Il ricorso, nella Comédie humaine, a metafore desunte direttamente dal campo dell'architettura consente a Balzac di riunire, nella sua opera, e di «rendere compatibili le più clamorose contraddizioni» (p. 31), avendo, sui lettori, una sorta di effetto di contagio quasi come se si trattasse di attirarli e di coinvolgerli in una «specie di rapinosa, irresistibile e quasi allucinatoria vertigine mimetica» (p.33). Luoghi di scrittura particolarmente ricchi di riferimenti e di prestiti tratti dall'universo dell'architettura - ma anche dalla pittura e dalla scultura - sono le prefazioni ai romanzi della Comédie humaine dove, non soltanto il momento della progettualità, ma soprattutto la fase di esecuzione dell'opera narrativa sono resi, dallo scrittore, in forma 
particolarmente efficace. Nella sua concezione d'insieme, l'edificio narrativo balzachiano, perennemente "in fieri", si presenta come un universo sovraffollato ma governato da leggi precise: tra queste, quella senza dubbio più innovativa riguarda «il ritorno aperiodico dei personaggi, il continuo intersecarsi delle loro vicende» che «provocano nel lettore un senso di vertigine come si trovasse a muoversi in un labirinto di specchi tra linee che si integrano, si correggono, subiscono scarti improvvisi ed espongono allo spettacolo di singolari anamorfosi» (p. 41).

Negli stessi anni in cui Balzac si sforza di fornire al proprio pubblico l'idea di un grande cantiere letterario in divenire, preoccupandosi, osserva l'A., di trovare «un possibile correlativo della Comédie humaine in un edificio immaginario piuttosto che in un edificio reale» (p. 46), Victor Hugo propone, nel 1832, in Notre-Dame de Paris, una visione apparentemente simile di questa metafora, ma, in realtà, profondamente diversa. Lavagetto si sofferma, in modo specifico, sul discorso di Claudio Frollo alla fine del primo capitolo del quinto libro, circa il carattere minaccioso dell'invenzione della stampa nei confronti dell'unità armonica di una costruzione architettonica, la cattedrale, concepita come libro «al cui interno si possono riconoscere senza sforzo lettere, sillabe, parole, frasi che si articolano in una grande unità, un libro che costituisce il punto più alto e il coronamento di un percorso secolare» (p. 50). Dopo Gutenberg, i rapporti di forza mutano e «l'architettura sembra progressivamente perdere la sua centralità» (p. 54); la bibbia di carta ha preso il posto della bibbia di pietra: bisogna ammirare e rispogliare in continuazione il libro scritto dell'architettura, scrive Hugo, "ma non si deve negare la grandezza dell'edificio che anche la stampa è in grado di erigere" (p. 55).

6 Con H.James e M. Proust, considerarti dall'A. nella parte finale del suo studio, assistiamo all'estrema e ratificata presa di coscienza dell'impossibilità di costruire il "grande edificio" sul modello balzachiano. Benché l'idea di costruzione costituisca, per l'autore della Recherche, la vera ragione ed il verso valore della sua opera, quel grande modello diventa impraticabile poiché «il centro è stato irreparabilmente perduto» (p. 78). 